\title{
A phase I clinical trial of dose escalation of lobaplatin in combination with fixed-dose docetaxel for the treatment of human solid tumours that had progressed following chemotherapy
}

\author{
YU PENG ${ }^{1}$, YUE-E LIU ${ }^{2}$, XIAO-CAN REN ${ }^{2}$, XUE-JI CHEN ${ }^{2}$, HUI-LING SU ${ }^{2}$, JIE ZONG ${ }^{2}$, \\ ZENG-LI FENG ${ }^{2}$, DONG-YING WANG ${ }^{2}$, QIANG LIN ${ }^{2 *}$ and XIAN-SHU GAO ${ }^{3 *}$ \\ ${ }^{1}$ Hebei North University, Zhangjiakou, Hebei $075000 ;{ }^{2}$ Department of Oncology, \\ North China Petroleum Bureau General Hospital of Hebei Medical University, Renqiu, Hebei 062552; \\ ${ }^{3}$ Department of Radiation Oncology, Peking University First Hospital, Xicheng, Beijing 100034, P.R. China
}

Received February 1, 2014; Accepted October 22, 2014

DOI: $10.3892 / \mathrm{ol} .2014 .2675$

\begin{abstract}
In this study, the maximum tolerated dose (MTD) of lobaplatin (LBP) when it was combined with docetaxel (TXT) for the treatment of solid tumours that had progressed following chemotherapy was determined, and toxicities to this regimen were evaluated. A modified Fibonacci method was used for the dose escalation of LBP. The patients received TXT (at a fixed dose of $60 \mathrm{mg} / \mathrm{m}^{2}$ ) on day one (d1) and LBP (at an initial tested dose of $30 \mathrm{mg} / \mathrm{m}^{2}$ ) on day two (d2) of a treatment cycle that was repeated every 21 days. Each dose group consisted of at least three cases. In the absence of dose-limiting toxicity (DLT), we proceeded to the next dose group, with a dose increment of $5 \mathrm{mg} / \mathrm{m}^{2}$ between groups, until DLT occurred. The dose immediately below the dose that produced DLT was regarded as the MTD. The 17 patients examined in this study completed a total of 58 cycles of chemotherapy, and a total of three dose-escalation groups $\left(30 \mathrm{mg} / \mathrm{m}^{2} \mathrm{LBP}, 35 \mathrm{mg} / \mathrm{m}^{2} \mathrm{LBP}\right.$, and $40 \mathrm{mg} / \mathrm{m}^{2} \mathrm{LBP}$ ) were established. The main adverse event that was observed was myelosuppression. DLT occurred in four patients, including three patients in the $40 \mathrm{mg} / \mathrm{m}^{2} \mathrm{LBP}$ group and one patient in the $35 \mathrm{mg} / \mathrm{m}^{2}$ LBP group. In total, three out of the four patients in the $40 \mathrm{mg} / \mathrm{m}^{2} \mathrm{LBP}$ group exhibited DLT. We determined that the treatment administered
\end{abstract}

Correspondence to: Dr Qiang Lin, Department of Oncology, North China Petroleum Bureau General Hospital of Hebei Medical University, 8 Huizhan Avenue, Renqiu, Hebei 062552, P.R. China

E-mail: zyy_linqiang@hotmail.com

Dr Xian-Shu Gao, Department of Radiation Oncology, Peking University First Hospital, 8 Xishiku Street, Xicheng, Beijing 100034, P. R. China

E-mail: billhappy001@163.com

*Contributed equally

Key words: dose escalation, lobaplatin, docetaxel, chemotherapy, neoplasm to the $35 \mathrm{mg} / \mathrm{m}^{2}$ LBP group represented the MTD. Thus, our phase I trial revealed that the MTD for the tested LBP combination regimen was $35 \mathrm{mg} / \mathrm{m}^{2} \mathrm{LBP}$ and $60 \mathrm{mg} / \mathrm{m}^{2} \mathrm{TXT}$. This regimen resulted in mild adverse reactions and favourable patient tolerance. Therefore, we recommend the use of these dosages in phase II clinical trials.

\section{Introduction}

Statistics indicate that the incidence of cancer in China is increasing each year (1). Moreover, the clinical diagnosis of many Chinese patients occurs when these individuals have late-stage cancer and therefore no longer have the opportunity to receive radical surgical treatment. Chemotherapy has become an important method of cancer treatment, however, most patients undergo either relapse or metastasis following first-line chemotherapy, requiring second-line and subsequent treatments.

Cisplatin (DDP)-based chemotherapy is significant in cancer treatment; however, due to its toxicity, particularly nephro- and neuro-toxicity, DDP-based chemotherapy has limited applications $(2,3)$. Therefore, researchers have pursued a new platinum compound. Lobaplatin (LBP), which is a class III platinum anticancer drug developed by the German firm ASTA Medica (Degussa), is primarily used for the treatment of advanced breast cancer, small cell lung cancer (SCLC), and chronic myeloid leukaemia (4). Research has demonstrated that LBP has various advantageous properties, including strong anticancer activity, no significant nephrotoxicity or neurotoxicity, no requirement for hydration/liquid infusion (5), a much lower incidence of drug resistance than DDP, and no cross-resistance with DDP $(6,7)$. The mechanism of action of LBP is similar to that of other platinum drugs; in particular, LBP induces the formation of inter-strand Pt-GG and Pt-AG crosslinks, blocking DNA replication and transcription and thereby inhibiting gene expression in tumour cells (6). LBP's pharmacokinetic characteristics include the rapid onset of clinical effects, the persistence of these effects for a long duration, high tumour tissue concentrations, and low plasma concentrations (8). Thus, the drug demonstrates 
good selectivity after entering the body. LBP exhibits superior pharmacokinetic parameters in Chinese populations compared with Western populations $(8,9)$. A number of studies have revealed that LBP has broad-spectrum anticancer activity, including efficacy against lung cancer, breast cancer, colorectal cancer, testicular cancer, and lymphoma $(2,10,11)$.

Docetaxel (TXT) is a semisynthetic compound in the taxane class of anti-cancer drugs. It binds to free tubulin, promotes the assembly of tubulin into stable microtubules, and inhibits microtubule depolymerisation (12). These effects significantly decrease the quantities of free tubulin and thereby inhibit cell mitosis and proliferation. Single-agent chemotherapy with TXT is an important treatment approach for a variety of tumours (13-16). Studies have demonstrated that the administration of LBP in combination with TXT can produce certain therapeutic effects in patients with tumour progression after chemotherapy and that in this combination, LBP and TXT produce synergistic effects (11). However, the optimal LBP dose in this combination regimen has not been established based on the findings from phase I/II clinical trials. In particular, although international studies have established a recommended LBP dose of $50 \mathrm{mg} / \mathrm{m}^{2}$ for single-agent chemotherapy (17-20), no phase I studies on the appropriate LBP dose in the aforementioned combination regimen for second-line or third-line chemotherapy have been reported. In Europe and the USA, the recommended dose of TXT for second-line therapy is $75-100 \mathrm{mg} / \mathrm{m}^{2}(21)$, however, Asian studies have suggested that a TXT dose of $60 \mathrm{mg} / \mathrm{m}^{2}$ is more suitable for East Asian populations (22-24). Our previous studies have demonstrated that Eastern and Western populations have different tolerances for the same doses of chemotherapy (cisplatin with 5-fluorouracil, and capecitabine with docetaxel), with tolerated doses in the combination regimens for Eastern populations that are equivalent to $70 \%$ to $80 \%$ of the corresponding doses for Western populations $(25,26)$. Therefore, it is unclear whether chemotherapy doses determined based on studies of Western populations can be applied to Chinese patients. To further investigate the appropriate LBP dose in the aforementioned combination regimen, we conducted a dose escalation trial for LBP in this regimen; this study reports the results of this trial.

\section{Materials and methods}

Eligibility. The patients who participated in this study were pathologically or cytologically confirmed to have advanced solid tumours that had progressed after at least first-line chemotherapy. These patients had at least one evaluable lesion $(27,28)$ and were in clinical stages III or IV. The following inclusion criteria were utilised: 18-75 years of age; Karnofsky Performance Status (KPS) score $\geq 60$, with expected survival of over three months; a complete recovery to normal from the toxicity of prior treatment, with $\geq$ four weeks since any previous treatment; marrow conditions that included a white blood cell (WBC) count, $\geq 4.0 \times 10^{9} / 1$, neutrophils, $\geq 1.5 \times 10^{9} / 1$, platelets (PLT), $\geq 100 \times 10^{9} / 1$, and haemoglobin, $\geq 100 \mathrm{~g} / \mathrm{l}$; adequate hepatic and renal function (serum creatinine, aspartate aminotransferase, alanine aminotransferase and total serum bilirubin supper limits of normal); normal cardiopulmonary function, with no obvious infection, gastrointestinal bleeding, or other serious visceral diseases; no prior treatment with LBP; no treatment with TXT during the previous six months; favourable compliance to the chemotherapy regimen during the study period; and the provision of written informed consent.

Exclusion criteria. Pregnant or lactating women; patients with no self-awareness, uncontrollable central nervous system metastases, uncontrollable seizures, or mental illnesses impairing self-awareness or judgment; patients who had been treated with chemotherapy drugs other than LBP and TXT or with radiation therapy within the prior four weeks; patients with organ transplants; and patients with the long-term use of immunosuppressive agents and corticosteroids.

Pretreatment evaluation. Within one week prior to the start of treatment, the researchers obtained the subjects' medical histories and KPS scores as well as completing a physical examination, a routine blood examination, tests of liver and renal function, chest and abdominal computed tomography (CT) imaging, and an electrocardiogram for each study subject.

Trial Design. The trial was an open-label, non-randomised dose escalation study. Each group consisted of at least three patients. The primary endpoint of this study was to determine the maximum tolerated dose (MTD) of LBP in a LBP and TXT combination regimen for the treatment of solid tumours with progression following chemotherapy. The secondary endpoint of the study was to evaluate the safety, toxicity, and time to progression (TTP) of this LBP and TXT combination regimen.

Ethics. The study was approved by the Ethics Committee, North China Petroleum Bureau General Hospital of Hebei Medical University, Renqiu, China. It was performed in accordance with the ethics standards of human experimentation and with the Helsinki Declaration of 1975, as revised in 2000. All patients provided written informed consent.

Chemotherapy. A fixed dose of $60 \mathrm{mg} / \mathrm{m}^{2}$ TXT was diluted in $250 \mathrm{ml}$ of $5 \%$ glucose and then intravenously injected on day one (d1) (22-24). LBP was dissolved in $5 \mathrm{ml}$ of injectable sterile water, diluted in $250 \mathrm{ml}$ of $5 \%$ glucose, and then intravenously injected in a $2 \mathrm{~h}$ treatment on day two (d2). A prophylactic anti-allergy treatment of $8 \mathrm{mg}$ of dexamethasone was administered twice per day on the three consecutive days of $\mathrm{d}-1, \mathrm{~d} 1$, and $\mathrm{d} 2$. This treatment cycle was repeated every 21 days for a minimum of two cycles. The treatment was continued until disease progression or unacceptable toxicity was observed, up to a maximum of six cycles of chemotherapy.

During therapy, all patients were given 5-hydroxytryptamine (HT3) receptor antagonists as an anti-emetic prophylactic treatment. To ensure the continuity of chemotherapy, at WBC $<4.0 \times 10^{9} / 1$ and/or absolute neutrophil count (ANC) $<2.0 \times 10^{9} / 1$, supportive treatment using recombinant human granulocyte colony-stimulating factor was administered, and when PLT $<75 \times 10^{9} / 1$, interleukin- 11 treatment was administered. If clinically indicated, additional supportive care was allowed. 
Dose escalation and the determination of dose-limiting toxicity $(D L T)$. The evaluation of adverse events was based on the Common Terminology Criteria for Adverse Events, v3.0 (29). DLT was defined to be the occurrence of one or more of the following events after the first day of chemotherapy and prior to the third cycle of chemotherapy: i) Haematological toxicity in the form of grade IV neutropenia, grade III febrile neutropenia, grade III or grade IV thrombocytopenia, or grade III or grade IV anaemia; ii) grade III-IV non-haematological toxicity (with the exception of alopecia, nausea, vomiting, and fatigue); and iii) any grade $\mathrm{V}$ responses.

A modified Fibonacci method (30) was used, with an initial LBP dose of $30 \mathrm{mg} / \mathrm{m}^{2}$ and a subsequent increase of $5 \mathrm{mg} / \mathrm{m}^{2}$ from one group to the next. The patients received the treatment specified by the study protocol in accordance with their order of enrolment, and the study gradually progressed from enrolling subjects in a low-dose group to enrolling subjects in a high-dose group. At least three patients were enrolled in each group. If DLT did not occur in the three cases in a dose group, the subsequent dose group was initiated. However, repeated administration to the same patient was not allowed. If one case of DLT occurred within a dose group, three additional patients were enrolled into the dose group in question. Enrolment into the subsequent dose group could only commence if none of these additional three patients experienced DLT. If one or more cases of DLT occurred among these additional three patients, the trial was terminated. The dose used in the final group was regarded as the dose that produced DLT, and the dose immediately below the dose that produced DLT was regarded as the MDT.

Evaluation Standards. We used RECIST (Response Evaluation Criteria in Solid Tumours) 1.1 to evaluate short-term efficacy (31). The time point at which the efficacy evaluation was performed was one week prior to the third chemotherapy cycle. The following classifications were used for this evaluation: complete remission (CR), partial response (PR), stable disease (SD), and progressive disease (PD). The response rate $(R R)$ was defined to be $C R+P R$, and the disease control rate (DCR) was defined to be $\mathrm{CR}+\mathrm{PR}+\mathrm{SD}$. The main image-based evidence used for these evaluations consisted of the $\mathrm{CT} / \mathrm{magnetic}$ resonance imaging (MRI) results. It was thought that with the exception of cases involving PD, no evaluations of efficacy could be performed after only one cycle of chemotherapy. Each patient received at least two cycles of chemotherapy. The chemotherapy cycle was repeated every 21 days, and treatment was continued until the occurrence of disease progression or unacceptable toxicity.

Subsequent treatment. Based on the judgements of the research team, patients with disease progression received either third-line treatment or the best available supportive care.

Follow-up. Following the completion of the treatment, the patients underwent follow-up studies once per month for the first six months and once every three months subsequently. Each follow-up exam included the acquisition of a medical history, a physical examination, a routine blood examination, comprehensive biochemical tests, and a chest $\mathrm{CT}$; in addition,
Table I. Patient characteristics

Characteristic

Patients, $\mathrm{n}$

\begin{tabular}{lc}
\hline Gender & \\
Male & 9 \\
Female & 8 \\
Age, year & \\
Range & $45-76$ \\
Median & 62 \\
Stage & \\
IIIA & 1 \\
IIIB & 2 \\
IV & 14 \\
KPS & \\
Range & $70-90$ \\
Median & 90
\end{tabular}

an abdominal CT was performed once every three months. All patients were followed up by outpatient examinations and telephone, and follow-up continued until mortality occurred.

Statistical analysis. Data analysis was performed using SPSS 18.0, and the Kaplan-Meier method was used to calculate patients' TTP.

\section{Results}

Patient characteristics. Between May 2012 and November 2013, 17 patients with malignant solid tumours were enrolled in this study. These patients included nine males and eight females, and their ages ranged from 45-76 years (with a median age of 62 years). The median KPS score of the study participants was 80 points (with a range of 60-90). Patients' body surface areas ranged from 1.41-1.94 $\mathrm{m}^{2}$ (median, $1.66 \mathrm{~m}^{2}$ ). There were 11 cases of non-small cell lung cancer (NSCLC), two cases of SCLC, two cases of breast cancer, one case of gastric cancer, and one case of endometrial carcinoma. There was one stage IIIA patient, two stage IIIB patients, and 14 stage IV patients. A total of 14 patients among the entire group of study subjects were evaluable for efficacy; all 17 patients were evaluable for toxicity (Table I). Until 5th January 2014, no cases had been lost to follow-up, and the follow-up rate was $100 \%$.

Compliance. A total of 17 patients completed a total of 58 cycles of chemotherapy. The median number of chemotherapy cycles completed by a patient was four (range, 1-6 cycles). Two patients completed one chemotherapy cycle, six patients completed two chemotherapy cycles, five patients completed four chemotherapy cycles, and four patients completed six chemotherapy cycles.

Haematological toxicity. Table II describes the haematological toxicities associated with the tested treatments. The incidence of leukopenia was $82.35 \%$ (11 cases), the incidence of grade III leukopenia was $29.41 \%$ (five cases), and there were no cases of grade IV leukopenia. The incidence of 
Table II. Haematological toxicities.

$\frac{30 \mathrm{mg} / \mathrm{m}^{2}}{\text { Cases, } \mathrm{n}} \quad \% \quad \frac{35 \mathrm{mg} / \mathrm{m}^{2}}{\text { Cases, } \mathrm{n}} \quad \% \quad \frac{40 \mathrm{mg} / \mathrm{m}^{2}}{\text { Cases, } \mathrm{n}}$

Leukopenia

\begin{tabular}{|c|c|c|c|c|c|c|}
\hline 0 & 1 & 33.3 & 1 & 10.0 & 1 & 25.0 \\
\hline I-II & 2 & 66.6 & 6 & 60.0 & 1 & 25.0 \\
\hline III & 0 & 0 & 3 & 30.0 & 2 & 50.0 \\
\hline IV & 0 & 0 & 0 & 0 & 0 & 0 \\
\hline \multicolumn{7}{|c|}{ Neutropenia } \\
\hline 0 & 3 & 100 & 3 & 30.0 & 1 & 25.0 \\
\hline I-II & 0 & 0 & 2 & 20.0 & 1 & 25.0 \\
\hline III & 0 & 0 & 4 & 40.0 & 1 & 25.0 \\
\hline IV & 0 & 0 & 1 & 10.0 & 1 & 25.0 \\
\hline \multicolumn{7}{|c|}{ Anemia } \\
\hline 0 & 2 & 66.6 & 4 & 40.0 & 1 & 25.0 \\
\hline I-II & 1 & 33.3 & 6 & 60.0 & 3 & 75.0 \\
\hline III & 0 & 0 & 0 & 0 & 0 & 0 \\
\hline IV & 0 & 0 & 0 & 0 & 0 & 0 \\
\hline \multicolumn{7}{|c|}{ Thrombocytopenia } \\
\hline 0 & 2 & 66.6 & 7 & 70.0 & 2 & 50.0 \\
\hline $\mathrm{I} \neg-\mathrm{II}$ & 1 & 33.3 & 3 & 30.0 & 1 & 25.0 \\
\hline III & 0 & 0 & 0 & 0 & 1 & 25.0 \\
\hline IV & 0 & 0 & 0 & 0 & 0 & 0 \\
\hline
\end{tabular}

Table III. Non-haematological toxicities.

\begin{tabular}{|c|c|c|c|c|c|}
\hline \multicolumn{2}{|c|}{$30 \mathrm{mg} / \mathrm{m}^{2}$} & \multicolumn{2}{|c|}{$35 \mathrm{mg} / \mathrm{m}^{2}$} & \multicolumn{2}{|c|}{$40 \mathrm{mg} / \mathrm{m}^{2}$} \\
\hline Cases, $\mathrm{n}$ & $\%$ & Cases, $\mathrm{n}$ & $\%$ & Cases, $\mathrm{n}$ & $\%$ \\
\hline 3 & 100 & 9 & 90.0 & 4 & 100 \\
\hline 0 & 0 & 1 & 10.0 & 0 & 0 \\
\hline 0 & 0 & 0 & 0 & 0 & 0 \\
\hline
\end{tabular}

Diarrhea

\begin{tabular}{|c|c|c|c|c|c|c|}
\hline 0 & 3 & 100 & 9 & 90.0 & 4 & 100 \\
\hline I-II & 0 & 0 & 1 & 10.0 & 0 & 0 \\
\hline III-IV & 0 & 0 & 0 & 0 & 0 & 0 \\
\hline \multicolumn{7}{|c|}{ Phlebitis } \\
\hline 0 & 3 & 100 & 9 & 90.0 & 4 & 100 \\
\hline I-II & 0 & 0 & 1 & 10.0 & 0 & 0 \\
\hline III-IV & 0 & 0 & 0 & 0 & 0 & 0 \\
\hline \multicolumn{7}{|l|}{ Fatigue } \\
\hline 0 & 3 & 100 & 6 & 60.0 & 3 & 75.0 \\
\hline I-II & 0 & 0 & 4 & 40.0 & 1 & 25.0 \\
\hline III-IV & 0 & 0 & 0 & 0 & 0 & 0 \\
\hline \multicolumn{7}{|l|}{ Nausea } \\
\hline 0 & 3 & 100 & 9 & 90.0 & 2 & 50.0 \\
\hline I-II & 0 & 0 & 1 & 10.0 & 2 & 50.0 \\
\hline III-IV & 0 & 0 & 0 & 0 & 0 & 0 \\
\hline \multicolumn{7}{|c|}{ Vomiting } \\
\hline 0 & 3 & 100 & 10 & 100 & 4 & 100 \\
\hline I-II & 0 & 0 & 0 & 0 & 0 & 0 \\
\hline III-IV & 0 & 0 & 0 & 0 & 0 & 0 \\
\hline
\end{tabular}


Table IV. Dose escalation level.

\begin{tabular}{lccc}
\hline Levels & Patients & Lobaplatin, $\mathrm{mg} / \mathrm{m}^{2}$ & Docetaxel, mg/m \\
\hline I & 3 & 30 & 60 \\
II & 10 & 35 & 60 \\
III & 4 & 40 & 60 \\
\hline
\end{tabular}

neutropenia was $58.82 \%$ (ten cases), the incidence of grade III neutropenia was $29.41 \%$ (five cases), and the incidence of grade IV neutropenia was $11.76 \%$ (two cases). The incidence of anaemia was $58.82 \%$ (ten cases), with no cases of grade III or grade IV anaemia. The incidence of thrombocytopenia was $46.2 \%$ (six cases), the incidence of grade III thrombocytopenia was $5.88 \%$ (one case in the $40 \mathrm{mg} / \mathrm{m}^{2}$ group), and there were no cases of grade IV thrombocytopenia.

Non-haematological toxicity. The subjects experienced only mild non-haematological toxicities of grades I-II. There were no treatment-related deaths. There was one case of diarrhoea $(5.88 \%)$, one case of phlebitis $(5.88 \%)$, five cases of fatigue $(29.41 \%)$, three cases of nausea $(17.65 \%)$, and no cases of vomiting. All the patients improved after receiving symptomatic treatment. The adverse events are detailed in Table III.

Determination of MTD. DLT did not occur in the chemotherapy group that received the initial LBP dose of $30 \mathrm{mg} / \mathrm{m}^{2}$, which was administered to the first three enrolled patients. In accordance with the dose escalation method, three patients were then enrolled into the next highest dose group, the $35 \mathrm{mg} / \mathrm{m}^{2}$ LBP group; as previously, DLT did not occur. Subsequently, four patients were enrolled into the next dose group (40 $\mathrm{mg} / \mathrm{m}^{2}$ LBP group); the first of these patients withdrew from the trial on the seventh day after the first cycle of chemotherapy due to associated pancreatitis. We hypothesise that this occurrence of pancreatitis, which caused the patient to succumb to the disease seven days following the onset, was not directly caused by the chemotherapy. This is due to the fact that a search of the literature did not identify any studies which reported that lobaplatin or docetaxel could induce pancreatitis, and pancreatitis was not mentioned as a side effect in the instructions for the two drugs. DLT occurred in the second patient. This patient experienced grade III thrombocytopenia with a PLT of $26 \times 10^{9} / \mathrm{L}$ on the $11^{\text {th }}$ day after one cycle of chemotherapy and succumbed to the disease on the day 12 following chemotherapy due to massive haemoptysis. This patient, who received only a single cycle of chemotherapy, exhibited central lung cancer with T4 lesions. On the third day following chemotherapy, pain and numbness in the patient's left arm were significantly reduced, and swelling on the left side of the patient's face had subsided significantly, suggesting that the chemotherapy was effective. Massive haemoptysis may have occurred due to damage to major blood vessels caused by rapid tumour regression (32); therefore, this patient's outcome was not considered to be a case of chemotherapy-related death. The third patient in the $40 \mathrm{mg} / \mathrm{m}^{2} \mathrm{LBP}$ group experienced grade IV neutropenia (a case of DLT), and the fourth patient in this group experienced grade III febrile neutropenia (a case of DLT). Therefore, at the third dose level, two patients each completed two cycles of chemotherapy, and experienced DLT (in the form of neutropenia), and one patient completed one cycle of chemotherapy, but also experienced DLT (in the form of grade III thrombocytopenia). We determined that the $40 \mathrm{mg} / \mathrm{m}^{2}$ level of LBP was the dose that produced DLT, and dose escalation was therefore terminated. To further evaluate the adverse events associated with $35 \mathrm{mg} / \mathrm{m}^{2} \mathrm{LBP}$, three additional patients were enrolled into the LBP $35 \mathrm{mg} / \mathrm{m}^{2}$ group. Among these patients, one case of DLT (in the form of grade IV neutropenia) was observed. Subsequently, an additional four patients were enrolled into this group, however, no other cases of DLT were observed. Therefore, in the $35 \mathrm{mg} / \mathrm{m}^{2}$ group, there were a total of 10 patients, and one case of DLT was observed. The patient who experienced DLT exhibited lung cancer with multiple bone metastases. This patient's poor bone marrow function may have contributed to the onset of grade IV neutropenia. The patient's neutrophil levels returned to normal after seven days, and no febrile neutropenia was observed. The aforementioned observations suggested that the $35 \mathrm{mg} / \mathrm{m}^{2}$ dose level was well tolerated; therefore, we do not consider this dose to be regularly associated with DLT. In summary, this study had three dose levels, as indicated in Table IV. Initially, three patients were enrolled in the dose group I, which consisted of $30 \mathrm{mg} / \mathrm{m}^{2} \mathrm{LBP}$ on $\mathrm{d} 2$ and $60 \mathrm{mg} / \mathrm{m}^{2}$ TXT on $\mathrm{d} 1$, and DLT did not occur. In total, 10 patients were enrolled in dose group II, which consisted of $35 \mathrm{mg} / \mathrm{m}^{2} \mathrm{LBP}$ on $\mathrm{d} 2$ and $60 \mathrm{mg} / \mathrm{m}^{2}$ TXT on $\mathrm{d} 1$, and only one patient experienced DLT. In contrast, four patients were enrolled in dose group III, which consisted of $40 \mathrm{mg} / \mathrm{m}^{2}$ LBP on $\mathrm{d} 2$ and $60 \mathrm{mg} / \mathrm{m}^{2}$ TXT on $\mathrm{d} 1$, however, one patient withdrew from the group, and the other three patients experienced DLT. These results suggested that in the tested regimen, the dose level of $40 \mathrm{mg} / \mathrm{m}^{2} \mathrm{LBP}$ was overly strong and was not tolerated by the patients. In accordance with our experimental design, we determined that the MTD was the highest tested dose less than the dose that produced DLT; therefore, the MTD for the tested regimen was $35 \mathrm{mg} / \mathrm{m}^{2}$ LBP on $\mathrm{d} 2$ and $60 \mathrm{mg} / \mathrm{m}^{2} \mathrm{TXT}$ on $\mathrm{d} 1$ of a treatment cycle that repeated every 21 days.

Short-term efficacy. Among the 17 examined patients, 14 patients were evaluable. Among these 14 patients, there were no cases of CR, one case of PR, 10 cases of SD, and three cases of PD. Thus, the RR was $7.1 \%$ (1/14), and the DCR was $78.6 \%(11 / 14)$. Among the 11 examined NSCLC patients, nine patients were evaluable. These patients included one case of PR, six cases of SD, and two cases of PD. Thus, among the NSCLC patients, the RR was $11.1 \%(1 / 9)$, and the DCR was $77.8 \%(7 / 9)$. 


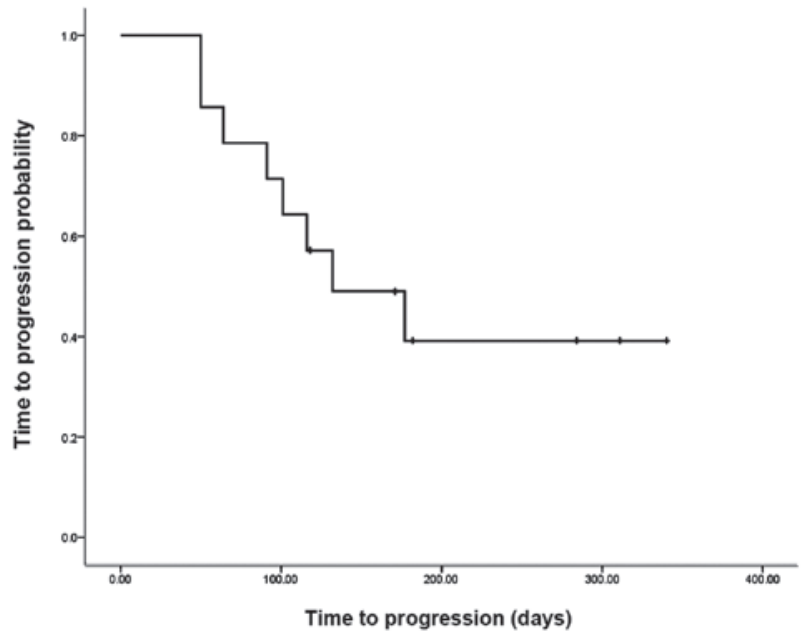

Figure 1. TTP for all patients: The median TTP was 132 days, and 6-months TTP rate was $39.2 \%$. TTP, time to progression.

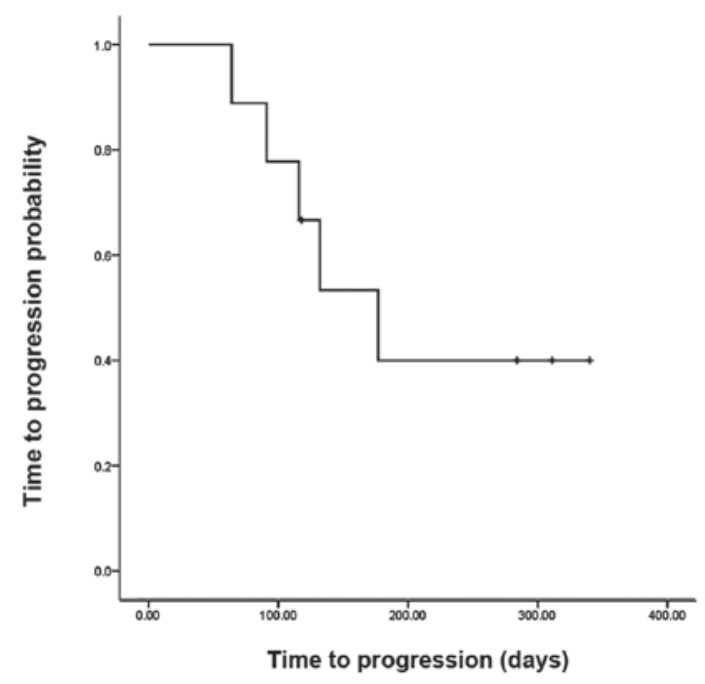

Figure 2. TTP for patients with NSCLC: The median TTP was 177 days, and the 6-month TTP rate was $40.0 \%$. TTP, time to progression.

Survival analysis. Although we conducted a phase I study, the follow-up time was not extensive, and the overall survival data are not yet available. However, we have reported the preliminary survival information in the current study. Fig. 1 indicates that the median TTP among all patients was 132 days, and the six month TTP rate was $39.2 \%$. Fig. 2 indicates that among the NSCLC patients, the median TTP was 177 days (95\% confidence interval: 100-255 days), and the 6-month TTP rate was $40 \%$.

\section{Discussion}

The current phase I dose escalation clinical trial demonstrated that the LBP and TXT combination regimen for the treatment of human solid tumours with progression following chemotherapy is safe, is associated with a low incidence of serious adverse effects, and exhibits short-term efficacy.

The wide application of DDP, carboplatin, and other platinum-based drugs in clinical antitumour therapies has led to the accumulation of overwhelming evidence indicating that platinum compounds have good therapeutic effects in the treatment of different types of cancer and that these compounds are currently among the most effective anticancer drugs in clinical use. However, as these drugs not only have significant renal toxicity and neurotoxicity, but also may cause auditory nerve damage as well as severe nausea and vomiting, the clinical applications of platinum-based drugs are subject to certain restrictions. Furthermore, the general physical condition and treatment tolerance are often poorer for patients receiving second-line therapy than for patients receiving first-line treatment. Therefore, current second-line treatment regimens frequently utilise drugs with lower toxicity and improved safety compared with platinum-based compounds.

DDP and the third-generation platinum compound, LBP have similar mechanisms of action. LBP has anti-cancer activity against a variety of tumours, including tumours resistant to DDP; LBP also produces only mild adverse gastrointestinal reactions, exhibits good water solubility, and has no significant nephrotoxicity or neurotoxicity $(33,34)$. LBP was researched and developed by the German company ASTA Medica (Degussa) (5). In 2002, the Chinese firm Hainan Chang'an International Pharmaceutical Co., Ltd. purchased the LBP patent and exclusive LBP production and marketing rights. In 2005, the State Food and Drug Administration (SFDA) of China approved LBP and subsequently LBP entered the Chinese market as a new Class I drug that was predominantly utilised for the treatment of advanced breast cancer, SCLC, and chronic myelogenous leukaemia. In China, LBP is generally administered at doses of $30-50 \mathrm{mg} / \mathrm{m}^{2}$, with a $50 \mathrm{mg} / \mathrm{m}^{2}$ dose used for single-agent chemotherapy with LBP and a $30 \mathrm{mg} / \mathrm{m}^{2}$ dose used for combination therapies; LBP treatment is typically repeated every three to four weeks (5). However, the aforementioned doses have not been determined through rigorous phase I/II clinical trials. In Germany, phase I/II clinical trials of LBP were conducted on Western subjects; the findings from these trials were used to establish a recommended dose of $50 \mathrm{mg} / \mathrm{m}^{2}$ for single-agent LBP therapy (17). However, considering the different tolerances for the same doses of chemotherapy between Eastern and Western populations, it is unclear whether dose recommendations based on studies of Western subjects are applicable to Eastern patients. Furthermore, no prior phase I/II studies of LBP doses in combination regimens were identified. Certain foundational studies have suggested that LBP and TXT exhibit synergistic antitumour effects when used in combination (11) and that TXT is a broad-spectrum antitumour drug that can effectively treat a variety of malignant solid tumours (35). In addition, studies from East Asia have demonstrated that the administration of $60 \mathrm{mg} / \mathrm{m}^{2}$ of TXT to Eastern patients is as effective as and less toxic than the administration of $75-100 \mathrm{mg} / \mathrm{m}^{2}$ of TXT to Western patients (22-24). This phenomenon may be associated with to a lack of CYP3A (cytochrome P450, family 3 , subfamily A) isoenzymes among Asian populations, given that these enzymes are involved in the metabolism of TXT to less active metabolites (22). Our previous studies have also found that the MTD for Chinese patients in a DDP and 5-fluorouracil combination regimen was equivalent to $70 \%$ of the corresponding MTD for Western patients (25). The aforementioned studies based on Asian populations have suggested 
that Eastern populations might have lower tolerances for doses of chemotherapy drugs than Western populations. Due to this, a phase I trial was conducted to identify MTDs in Eastern subjects; this clinical trial investigated LBP in combination with TXT to determine the MTD of LBP in this combination regimen.

Among the four cases of DLT in the current study, three cases of neutropenia were observed; by contrast, other studies have reported DLT occurring in the form of severe thrombocytopenia (17). In multiple clinical trials, the incidence of grade III-IV thrombocytopenia in LBP monotherapy (at $50 \mathrm{mg} / \mathrm{m}^{2}$ ) has ranged from $26.0 \%-72.7 \%(3,18,19)$. In studies of combination chemotherapy regimens involving LBP, typically at a dose of $30 \mathrm{mg} / \mathrm{m}^{2}$, the incidence of grade III-IV thrombocytopenia has ranged from 5.0\%-23.8\% (12,36); therefore, this incidence is markedly lower in combination chemotherapy compared with single-agent chemotherapy. Therefore, we considered the possibility that in the aforementioned studies, the incidence of chemotherapy-induced thrombocytopenia primarily correlated with the LBP dose. The $30 \mathrm{mg} / \mathrm{m}^{2} \mathrm{LBP}, 35 \mathrm{mg} / \mathrm{m}^{2} \mathrm{LBP}$, and $40 \mathrm{mg} / \mathrm{m}^{2} \mathrm{LBP}$ groups were established. The incidence of grade III-IV thrombocytopenia in the current study was $5.9 \%$ (1/17). The analysed LBP doses $\left(30-40 \mathrm{mg} / \mathrm{m}^{2}\right)$ were lower than the LBP dose used for single-agent chemotherapy $\left(50 \mathrm{mg} / \mathrm{m}^{2}\right)$, and the observed incidence of grade III-IV thrombocytopenia (5.9\%) was also lower in our study compared with previous studies of LBP monotherapy $(26.0 \%-72.7 \%)(3,18,19)$. In the current study, the observed case of grade III thrombocytopenia occurred in the $40 \mathrm{mg} / \mathrm{m}^{2}$ group, further indicating that the incidence of thrombocytopenia is associated with the LBP dose. In this study, the majority of observed toxicities were mild to moderate, and symptomatic treatment enabled a return to normal following the adverse events. Therefore, patients exhibited a favourable tolerance for the tested regimen.

In the current study, the RR was $7.1 \%(1 / 14)$, and the DCR was $78.6 \%$ (11/14). Among NSCLC patients, the RR was $11.1 \%$ (1/9), and the DCR was $77.8 \%$ (7/9). However, He et al (37) reported that, for the second-line treatment of NSCLC with $30 \mathrm{mg} / \mathrm{m}^{2} \mathrm{LBP}$ in combination with $75 \mathrm{mg} / \mathrm{m}^{2} \mathrm{TXT}$, an RR of $26.7 \%(4 / 15)$ and a DCR of $73.3 \%(11 / 15)$ were observed. Zhang et al (12) reported that, among patients with anthracycline-resistant advanced breast cancer who were treated with $30 \mathrm{mg} / \mathrm{m}^{2} \mathrm{LBP}$ in combination with $75 \mathrm{mg} / \mathrm{m}^{2} \mathrm{TXT}$, an RR of $54.8 \%$ (23/42) and a DCR of $80.9 \%$ (34/42) were observed. The current study reported a lower RR than those reported previously $(12,37)$. The following reasons may contribute to explaining this difference. Firstly, significantly higher treatment efficacy has been observed for the second-line treatment of breast cancer compared with that for the second-line treatment of NSCLC. The patients enrolled in the current study predominantly suffered from NSCLC, which was involved in $64.7 \%(11 / 17)$ of the cases that were examined. It was found that the efficacy of second-line chemotherapy for NSCLC was lower than that for breast cancer. However, Zhang et al (12) recruited patients with breast cancer and in the present study the majority of patients exhibited NSCLC. Thus, RR in the current study may have been lower than that reported by Zhang et al (12) due to patient differences. Secondly, this study included several patients who were receiving third-line
NSCLC treatments. These patients accounted for $27 \%(3 / 11)$ of the examined cases of NSCLC. By contrast, the NSCLC study by He et al (37) involved only second-line treatment groups. The DCR calculated in the current study was consistent with the DCRs calculated in the aforementioned reports by Zhang et al (12) and He et al (37).

In the current study, the median TTP among NSCLC patients was 177 days (95\% confidence interval: 74-163 days). In a review of second-line treatment for advanced NSCLC, Weiss et al (38) determined that the median TTP for second-line NSCLC treatment using cytotoxic chemotherapy agents ranged from 55 to 87 days and that the median TTP for second-line NSCLC treatment using epidermal growth factor receptor tyrosine kinase inhibitors varied from 48 to 108 days. The TTP in the current study was highly comparable with the findings by Weiss et al (38) in the review of second-line treatment for NSCLC; furthermore, 27\% (3/11) of NSCLC patients in the current study were third-line patients. Therefore, with respect to both disease control rate and median TTP, these findings are encouraging.

In conclusion, the MTD for the examined LBP combination regimen was $35 \mathrm{mg} / \mathrm{m}^{2} \mathrm{LBP}$ on $\mathrm{d} 2$ and $60 \mathrm{mg} / \mathrm{m}^{2} \mathrm{TXT}$ on d1 of a treatment cycle that was repeated every 21 days. We are utilising these dosages in a prospective phase II study to further evaluate the efficacy and safety of the proposed MTD.

\section{References}

1. Chen WQ, Zheng RS, Zeng HM, Zhang SW, Li N, Zou XN and He J: Trend analysis and prediction of cancer incidence in China. Zhonghua Yu Fang Yi Xue Za Zhi 46: 581-586, 2012 (In Chinese).

2. Harstrick A, Bokemeyer C, Scharnofkse M, Hapke G, Reile D and Schmoll HJ: Preclinical activity of a new platinum analogue, lobaplatin, in cisplatin-sensitive and -resistant human testicular, ovarian, and gastric carcinoma cell lines. Cancer Chemother Pharmacol 33: 43-47, 1993.

3. Gietema JA, Guchelaar HJ, de Vries EG, Aulenbacher P, Sleijfer DT and Mulder NH: A Phase I study of lobaplatin (D-19466) administered by $72 \mathrm{~h}$ continuous infusion. Anticancer Drugs 4: 51-55, 1993

4. Lai SQ and Xu M: Antineoplastic-lobaplatin. Shi Jie Lin Chuang Yao Wu 26: 315, 2005 (In Chinese).

5. Yang LQ and Qin SK: Progression of lobaplatin as the third generation platinum drug. Lin Chuang Zhong Liu Xue Za Zhi 14: 1134-1139, 2009 (In Chinese).

6. Mckeage MJ: Lobaplatin: a new antitumor platinum drug. Expert Opin Investig Drugs 10: 119-128, 2001.

7. Saris CP, van De Vaart PJ, Rietbroek RC and Blommaert FA: In Vitro formation of DNA adducts by cisplatin, lobaplatin and oxaliplatin in calf thymus DNA in solution and in cultured human cells. Carcinogenesis 17: 2763-2769, 1996.

8. Shi J, Yuan ZF,Liu WN, et al: Study on Lobaplatin Pharmacokinetic in Human Plasma and Tumor Tissue of Malignant Patients. Zhongguo Yaoxue Zazhi 24: 1888-1891, 2007 (In Chinese).

9. Welink J, Pechstein B and van der Vijgh WJ: Determination of the two diastereoisomers of lobaplatin (D-19466) in plasma ultrafiltrate of cancer patients with a normal or an impaired kidney or liver function by high-performance liquid chromatography with ultraviolet detection. J Chromatogr B Biomed Appl 675: 107-111, 1996.

10. Deng QQ, Huang XE, Ye LH, Lu YY, Liang Y and Xiang J: Phase II trial of Loubo® (Lobaplatin) and pemetrexed for patients with metastatic breast cancer not responding to anthracycline or taxanes. Asian Pac J Cancer Prev 14: 413-417, 2013.

11. Xie CY, Xu YP, Jin W and Lou LG: Antitumor activity of lobaplatin alone or in combination with antitubulin agents in non-small-cell lung cancer. Anticancer Drugs 23: 698-705, 2012.

12. Zhang Y, Liu Y G and Sun H: Clinical observation of docetaxel plus lobaplatin in treating anthracyclines resistant advanced breast cancer. Xian Dai Zhong Liu Xue Za Zhi 3: 473-474, 2011 (In Chinese). 
13. Chouaid C, Atsou K, Hejblum G and Vergnenegre A: Economics of treatments for non-small cell lung cancer. Pharmacoeconomics 27: 113-125, 2009.

14. Dancey J, Shepherd FA, Gralla RJ and Kim YS: Quality of life assessment of second-line docetaxel versus best supportive care in patients with non-small-cell lung cancer previously treated with platinum-based chemotherapy: results of a prospective, randomized phase III trial. Lung Cancer 43: 183-194, 2004.

15. Davies AM, Lara PN Jr, Mack PC and Gandara DR: Docetaxel in non-small cell lung cancer: a review. Expert Opin Pharmacother 4 553-565, 2003

16. Nabholtz JM and Crown J: Phase III studies of single-agent docetaxel in patients with metastatic breast cancer who have progressed despite previous chemotherapy regimens: preliminary results. Semin Oncol 25: 4-9, 1998.

17. Fiebig HH, Henß H, Mross K, et al: Phase I clinical trial of lobaplatin (D-19466) after intravenous bolus injection. Onkologie 17: 142-148, 1994.

18. Manegold C, Drings P, Gatzemeier U, Pawel Jv, Fiebig HH, Queißer W and Edler L: Lobaplatin (D-19466) in Patients with Advanced Non-Small-Cell Lung Cancer: A Trial of the Association for Medical Oncology (AIO) Phase II Study Group. Onkologie 19: 248-251, 1996.

19. Degardin M, Armand JP, Chevallier B, Cappelaere P, Lentz MA David $\mathrm{M}$ and Roché $\mathrm{H}$ : A clinical screening cooperative group phase II evaluation of lobaplatin (ASTA D-19466) in advanced head and neck cancer. Invest New Drugs 13: 253-255, 1995.

20. Kavanagh JJ, Edwards CL, Freedman RS, et al: A trial of lobaplatin (D-19466) in platinum-resistant ovarian cancer. Gynecol Oncol 58 106-109, 1995.

21. Huisman C, Smit EF, Giaccone G and Postmus PE: Second-line chemotherapy in relapsing or refractory non-small-cell lung cancer: a review. J Clin Oncol 18: 3722-3730, 2000.

22. Lai CL, Tsai CM, Chiu CH, Wang GS, Su WJ, Chen YM and Perng RP: Phase II randomized trial of tri-weekly versus days 1 and 8 weekly docetaxel as a second-line treatment of advanced non-small cell lung cancer. Jpn J Clin Oncol 35: 700-706, 2005.

23. Kunitoh H, Watanabe K, Onoshi T, Furuse K, Niitani H and Taguchi T: Phase II trial of docetaxel in previously untreated advanced non-small-cell lung cancer: a Japanese cooperativestudy. J Clin Oncol 14: 1649-1655, 1996.

24. Nakamura Y, Kunitoh H, Kubota K, Sekine I, Yamamoto N, Tamura $\mathrm{T}$, et al: Retrospective analysis of safety and efficacy of low-dose docetaxel $60 \mathrm{mg} / \mathrm{m} 2$ in advanced non-small cell lung cancer patients previously treated with platinum-based chemotherapy. Am J Clin Oncol 26: 459-464, 2003.

25. LinQ,GaoXS, QiaoXY,etal:Phase Itrial of escalating-dosecisplatin with 5-fluorouracil and concurrent radiotherapy in Chinese patients with esophageal cancer. Acta Med Okayama 62: 37-44, 2008.
26. Lin Q, Liu YE, Chang CL, et al: Phase I trial of dose escalation of capecitabine combined with fixed docetaxel in previously treated patients with non-small cell lung cancer. Chinese-German Journal of Clinical Oncology 11: 6-10, 2012.

27. Ardizzoni A, Tiseo M, Boni L, et al: Pemetrexed versus pemetrexed and carboplatin as second-line chemotherapy in advanced non-small-cell lung cancer: results of the GOIRC 02-2006 randomized phase II study and pooled analysis with the NVALT7 trial. J Clin Oncol 30: 4501-4507.

28. Kim HJ, Yun J, Kim HJ, et al: Phase II study of palliative S-1 in combination with cisplatin as second-line chemotherapy for gemcitabine-refractory pancreatic cancer patients. Oncol Lett 3: 1314-1318.

29. DCTD, NCI, NIH and DHHS: Cancer Therapy Evaluation Program, Common Toxicity Criteria for Adverse Events, Version 3.0. http://ctep.cancer.gov/protocolDevelopment/electronic_applications/docs/ctcaev3.pdf. Accessed October 30, 2014.

30. Ratain MJ, Mick R, Schilsky RL and Siegler M: Statistical and ethical issues in the design and conduct of phase I and II clinical trials of new anticancer agents. J Natl Cancer Inst 85: 1637-1643, 1993.

31. Eisenhauer EA, Therasse P, Bogaerts J, et al: New response evaluation criteria in solid tumours: revised RECIST guideline (version 1.1). Eur J Cancer 45: 228-247, 2009.

32. Cho KH, Ahn SJ, Pyo HR, et al: A Phase II study of synchronous three-dimensional conformal boost to the gross tumor volume for patients with unresectable Stage III non-small-cell lung cancer: results of Korean Radiation Oncology Group 0301 study. Int J Radiat Oncol Biol Phys 74: 1397-1404, 2009.

33. Ali I, Wani WA, Saleem K and Haque A: Platinum compounds: a hope for future cancer chemotherapy. Anticancer Agents in Med Chem 13: 296-306, 2013.

34. Wheate NJ, Walker S, Craig GE and Oun R: The status of platinum anticancer drugs in the clinic and in clinical trials. Dalton Trans 39: 8113-8127, 2010.

35. Cortes JE and Pazdur R. Docetaxel. J Clin Oncol 13: 2643-2655, 1995.

36. Yang LQ, Shi Y, Qin SK, et al: Clinical study of Lobaplatin combined with Navelbine for advanced non-small cell lung cancer. Lin Chuang Zhong Liu Xue Za Zhi 12: 890-894, 2006 (In Chinese).

37. He AB, Luo YX, Wang Q, Tong WX and Liu AH: The efficacy of lobaplatin combined with docetaxel versus docetaxel alone as the second-line treatment for advanced non-small cell lung cancer. Lin Chuang Zhong Liu Xue Za Zhi 10: 923-926, 2012 (In Chinese).

38. Weiss JM and Stinchcombe TE: Second-Line Therapy for Advanced NSCLC. Oncologist 18: 947-953, 2013. 